\title{
INTENTO DE SUPERVIVENCIA EN EL OCASO DE UNA CULTURA: LOS LIBROS PLÚMBEOS DE GRANADA
}

Puede decirse que en 1492 Granada cae, cual fruta madura, tanto por su total aislamiento respecto a los estados islámicos orientales y norteafricanos como por propia asfixia y las desavenencias internas, aunque su entrega definitiva haya sido el resultado de la presión militar y a la vez de intensas y hábiles negociaciones por parte de los cristianos con los personajes y grupos más representativos en el control de la ciudad. El hecho iba a tener, sin duda, trascendencia singular, ya que para los cristianos significaba la culminación de una empresa que había durado cerca de ocho siglos y la recuperación de su unidad nacional, mientras para los musulmanes representaba la supresión definitiva de su poder político en España, sin la posibilidad de que los vencidos pudiesen emigrar a otras ciudades o tierras de al-Andalus, como había sido normal a lo largo de toda la reconquista.

La esperanza de los mudéjares granadinos se cifraba, por tanto, en la emigración, sobre todo a tierras norteafricanas, y en las capitulaciones concertadas para la entrega de la ciudad, que les garantizaban el libre ejercicio de su religión y les permitían conservar su ley, su lengua, sus trajes y costumbres ${ }^{1}$. Esta esperanza se mantiene, aunque con explicables altibajos, en los años inmediatos a la conquista y antes del primer alzamiento de los mudéjares del Albaicín

${ }^{1}$ El texto de las Capitulaciones puede verse en LUIS DE MÁRMOL CARVAJAL, Historia de la rebelión y castigo de los moriscos del reino de Granada. $B A E$, t. 21, 1946, pp. 147-150; reproducido por MERCEDES GARCIA ARENAL, Los moriscos, Madrid, 1975, pp. 19-28. Cf., asimismo, MIGUEL GARRIDO ATIENZA, Las Capitulaciones para la entrega de Granada, Granada, 1910; MA. RIANO GASPAR REMIRO, Últimos pactos y correspondencia entre los Reyes Católicos y Boabdil sobre la entrega de Granada, Granada, 1910; J. MORENo CASADo, "Las Capitulaciones de Granada en su aspecto jurídico", en BUG, 21 (1949), 301-331. 
en 1499, en parte provocado por las disposiciones del cardenal Cisneros en materia catequética.

Hasta entonces los Reyes Católicos habían procurado observar las capitulaciones otorgadas e incluso habían resistido las presiones de quienes les insinuaban una política de mano dura y les aconsejaban la obligatoriedad de la conversión; por el contrario, ordenaban a los gobernadores y políticos de sus reinos que favoreciesen a los vencidos y no consintieran que fuesen agobiados y, menos, maltratados, a la vez que exhortaban a los prelados y religiosos a que, con blandura y amor, les enseñasen la fe católica².

Esta actitud de los soberanos no parece obedeciese, sin embargo, a que no consideraban todavía la tierra bien asegurada, por cuanto los moros aún no habían dejado totalmente las armas ${ }^{3}$, sino, tal vez, a que abrigaban el propósito de nuevas conquistas en territorios musulmanes - sin duda, norteafricanos - y convenía al favorable resultado de las mismas que sus reales palabras no fuesen puestas en entredicho.

La chispa inicial que prendió en el Albaicín y en otras comarcas granadinas a final del siglo XV, y en cuya extinción hubo de intervenir personalmente el rey Fernando, si bien no hizo cambiar radicalmente la posición de los soberanos, fue el primer lance que les aconsejó mayor cautela ante las posibles connivencias de los vencidos con los musulmanes de allende e incluso con los turcos, cuya presencia en el Mediterráneo occidental se iba a intensificar de manera progresiva. A este propósito hemos de recordar la extensa casida - 105 versos - enviada por un morisco anónimo al sultán otomano Báyazìd II (1481-1512) en demanda de ayuda; en ella se reflejan las apremiantes dificultades de los moriscos y se alude a ciertos hechos históricos, entre ellos la quema de los manuscritos árabes en Granada [por orden de Cisneros], la embajada egipcia a los Reyes Católicos, amenazando con represalias sobre los cristianos que allá moraban si en España se obligaba a la conversión de los musulmanes, etc. La casida fue estudiada, editada y traducida al inglés por James T. Monroe ${ }^{4}$, quien, apoyándose en los hechos en ella aludidos, la fecha en 1501, año en el que precisamente se ordena la conversión de los mudéjares granadinos.

\footnotetext{
${ }^{2}$ FRANCISCO BERMÚdEZ DE PEDRAZA, Historia eclesiástica de la ciudad de Granada, Granada, 1638, p. 195.

${ }^{3}$ MÁrmol, Historia... , ed. cit., p. 153.

4 "A curious morisco appeal no the Ottoman empire", AlAn, 31 (1966), 281-303; GARCÍA ARENAL (op. cit., pp. 33-41) nos ofrece la traducción española de dicha casida, precedida de una nota introductoria.
} 
Sin embargo, no parece que ese previsible riesgo exterior fuese lo que indujo a los reyes a conducirse con mayor precaución, sino más bien factores de índole interna, que presagiaban como utópica la asimilación de los moriscos. En efecto, a medida que el tiempo avanzaba, se percibía con mayor claridad el ambiente de tensión que latía entre aquéllos y los cristianos viejos, tensión que, a pesar de ciertas expectativas de disuasión, se iría acentuando en la primera mitad del siglo XVI.

Los factores determinantes de aquel clima enrarecido fueron muy diversos y han de cargarse en la cuenta respectiva de vencedores y vencidos: a los primeros les faltó voluntad decidida de asimilar a los moriscos, mientras a éstos les sobró tenacidad para atrincherarse en la segregación de su grupo. Esta resistencia se refleja, por lo general, en los aspectos más significativos de su comportamiento individual, familiar y social, donde el morisco se movía, casi siempre, entre la ficción y la insinceridad del supuesto cristiano, pero, en realidad, musulmán convencido.

Ocupaban el primer lugar sus creencias religiosas - de ordinario clandestinamente profesadas y defendidas - , en íntima conexión con la pervivencia de las fiestas musulmanas, oraciones coránicas y toda una serie de celebraciones ocultas y en cierto modo superpuestas a las ceremonias cristianas del bautismo, matrimonio, etc., con la secreta intención de anular, si posible fuera, el efecto de nuestros sacramentos en la persona que los había recibido 5 .

A esto se sumaba la conservación de sus linajes, el empleo de sus nombres musulmanes, además de los cristianos, el uso de la "algarabía" o árabe dialectal, junto con el uso de voces y expresiones arcaicas del romance e incluso, a veces, no más que el peculiar acento y pronunciación del mismo, que herían de manera sensible el oído del cristiano viejo, de habla netamente castellana $y$, en general, de poca cultura ${ }^{6}$.

Por último, la singularidad de sus trajes, que, no obstante ciertos cambios y obligadas simplificaciones, todavía representaban un claro elemento diferencial, lo mismo que el rechazo de

\footnotetext{
${ }^{5}$ Para ese punto todavía sigue siendo muy útil la obra de PEDRo LONGĀS, Vida religiosa de los moriscos, Madrid, 1915.

${ }^{6}$ En cuanto a la importancia de los linajes en la vida de los últimos musulmanes españoles y luego entre los muriscos, véase Julio Caro Baroja, Los moriscos del reino de Granada. Ensayo de historia social, Madrid, 1957, pp. 39-53.
} 
ciertos alimentos - carne de cerdo y vino, sobre todo-, el uso de los baños e incluso la manera de sentarse, siempre en el suelo y nunca en sillas o bancos. Todo esto, que hacía de los moriscos un grupo social cerrado y casi impermeable a influencias extrañas, había llegado a formar en su ánimo un conjunto inalterable, en el que facetas obviamente secundarias, como por ejemplo, el uso de su peculiar indumentaria, revestían para el morisco casi igual importancia que sus mismas creencias. En relación con ello, se mostraban vivamente refractarios a la instrucción religiosa que por parte cristiana se intentaba darles e incluso organizaban la enseñanza de sus hijos, cuando les resultaba factible, de acuerdo con su propia formación.

En definitiva, dos estilos de vida contrapuestos bajo muchos aspectos, lo cual no sólo hacía difícil la convivencia de ambas comunidades, sino que las empujó paulatinamente a una constante oposición, a un claro enfrentamiento y a una viva tensión polémica, lo mismo en la vida cotidiana y a nivel popular que en el plano superior de los intelectuales; esta polémica, generalmente oculta por miedo a la Inquisición, aparecía siempre avivada por los juicios y acusaciones que cada una de las partes formulaba y difundía respecto de la otra, sin el menor intento, no ya de mutua comprensión, mas ni siquiera de simple aproximación.

Sabido es cómo dicha polémica, que en España era ya anterior a la conquista de Granada y no había de extinguirse incluso con la misma expulsión de los moriscos, ha sido luminosamente estudiada por Louis Cardaillac en su libro Morisques et chrétiens. Un affrontement polémique $(1492-1640)^{7}$, libro bien reciente -la edición francesa es de 1977 - , pero ya clásico en la materia y que su prologuista, Fernand Braudel, ha podido emparejar, por su calidad excepcional, con la obra maestra de Marcel Bataillon Erasmo y España.

Consecuencia de la situación ya apuntada, como advierte el mismo Cardaillac, es que "Las relaciones cotidianas de las dos comunidades se verán falseadas por esta lucha y estarán marcadas por la ambigüedad: amistad y traición, fidelidad y perjurio, conversión forzada y celo religioso se darán juntos"8.

Pero este ambiente de soterrada tensión - a veces exteriorizada - se agrava todavía más en el tercer cuarto del siglo XVI, al entrar en acción determinados factores por parte de los cristianos.

\footnotetext{
${ }^{7}$ Moriscos y cristianos. Un enfrentamiento polémico (1492-1640). Tra. ducción española de M. García Arenal, Madrid, 1979, por la que cito.

${ }^{8}$ LOUIS CARDAILlac, op. cit., p. 16.
} 
El primero, y acaso germen de todos los demás, fue la disparidad de criterio entre el Capitán General de Granada y la Real Chancillería, es decir, entre la nobleza y la clase militar que de ella dependía, por una parte, y, por otra, el estamento representado por los nuevos letrados, cuyo poder se acentúa progresivamente en el reinado de Felipe II; problema derivado, en realidad, de la oposición entre personalidades formadas en un ambiente renacentista y tolerante, como fuera el del emperador Carlos V, y los paladines del espíritu intransigente, rígido y austero de la Contrarreforma, propio ya de la época de Felipe II. Esta rivalidad, que los historidadores de la contienda señalan como una de las causas principales de la sublevación morisca de 1568, alcanza su punto culminante siendo presidente de la Chancillería Pedro de Deza y capitán general fñigo López de Mendoza, tercer marqués de Mondéjar y cuarto conde de Tendilla, en quien los moriscos tenían puesta su mayor esperanza.

Efecto de este antagonismo y del creciente predominio de las gentes de la Chancillería son dos hechos que, sin duda, ostentan la primacía entre los que más decisivamente habrían de influir en el ánimo de los moriscos, empujándolos a la sublevación ya aludida. El primero radica en la petición formulada por los letrados, poco antes de 1560 , para que fuesen revisados todos los títulos de propiedad en el reino de Granada, revisión que, como cabía suponer, perjudicó en mayor grado a los moriscos, quienes debían presentar títulos antiguos del tiempo de la dinastía nazarí o, de lo contrario, eran inexorablemente despojados de sus propiedades y haciendas, que de nuevo se ponían en venta. La gravedad de esta decisión alcanzaría límites extremos por la indiscriminada aplicación que de la misma hicieron sus ejecutores, según advierte certeramente Diego Hurtado de Mendoza9.

Sin embargo, lo que iba a colmar la paciencia de los moriscos y precipitar el estallido final, sería la pragmática aprobada el 17 de noviembre de 1566 y promulgada el 1 de enero de 1567: en ella se les prohibía, entre otras cosas, leer y escribir en árabe, poseer libros en esta lengua "de cualquier materia y calidad" y formular contratos en la misma bajo pena de nulidad; usar sus trajes peculiares -debiendo vestir a la castellana y las mujeres llevar el rostro destapado-, practicar sus ritos en bodas, desposorios y otras fiestas con zambras, leilas con instrumentos y cantores

9 "De la guerra de Granada", ed. crítica de M. Gómez-Moreno, Memorial Histórico Español, 49 (1948), 11-12. 
moriscos ${ }^{10}$, cerrar las puertas de sus casas, usar los baños y poseer esclavos gacís y negros ${ }^{11}$.

Aunque para la mentalidad morisca todos estos elementos representaban un todo homogéneo, según hemos adelantado ya, es indudable que el idioma significaba para ellos algo vital y que estimaban ligado a su propia fe; por tal motivo, y ponderando la dificultad de aprender rápidamente el castellano, habían procurado obtener para ello repetidas prórrogas, si bien con la oculta ilusión de seguir conservando su propia lengua. De hecho, las comarcas más islamizadas en el momento de la expulsión eran aquéllas que mejor habían conservado su lengua ${ }^{12}$.

Los moriscos, que recibieron la pragmática con profundo desagrado y contenida excitación, aún realizaron un último esfuerzo para suspender o, al menos, aplazar su ejecución, encomendando la defensa de su lengua, sus trajes y costumbres a uno de su propia raza, el anciano caballero Francisco Núñez Muley, morisco de gran prestigio entre los suyos y muy considerado por las autoridades locales. Tras haber sido paje del primer arzobispo de Granada, fray Hernando de Talavera, en 1513 interviene ante Fernando el Católico en favor de los moriscos, en 1518 acompaña al marqués de Mondéjar a la Corte con finalidad similar, y en 1526 se le encomienda por los suyos dar las gracias al emperador Carlos V - que a la sazón pasaba en Granada su luna de miel con Isabel de Portugal - por haber suspendido, a cambio de un elevado tributo, ciertas disposiciones anteriormente adoptadas contra los moriscos.

En la serena, ponderada y hábil defensa enviada por Núñez Muley al presidente de la Chancillería Pedro de Deza, y después de recordar el cambio operado tras la muerte de los Reyes Católi-

${ }^{10}$ Para las fiestas de carácter profano celebradas por los moriscos, véase la obra postuma - por mí editada - de ANTONIO GALLEGo BURÍn y ALFONSO GÁMIR SANDOVAL, Los moriscos del reino de Granada según el sínodo de Guadix de 1554, Universidad de Granada, 1968, pp. 89-98.

${ }^{11}$ El esclavo gacís o gazís (del árabe gazí 'combatiente') era el que había llegado a semejante estado por cautiverio, ya fuese turco, árabe o cristiano, libre o rescatado. El contenido de la pragmática se halla recogido en MÁRMOL, Historia, p. 161.

${ }^{12}$ Como advierte JOAN FUSTER en su obra Poemas, moriscos y curas, Madrid, 1969, p. 123, y subraya L. CARDILLAC, $o p$. cit., p. 145, para las gentes del siglo XVI la lengua tenía un valor nacional e imponerla a sus vasallos y a las minorías significaba un avance en la política de asimilación; de ahí los esfuerzos de las autoridades españolas a fin de que los moriscos aprendiesen el castellano. Acerca de la lengua de los moriscos, véase la obra de Fuster, pp. 123-132. 
cos con sus hermanos de raza, intenta demostrar que las peculiaridades de los moriscos señaladas en la pragmática son sólo costumbres y usos regionales sin el menor propósito de segregación:

Cuando los naturales deste reino se convirtieron á la fe de Jesucristo, ninguna condición hubo que les obligase a dejar el hábito ni la lengua, ni las otras costumbres que tenían de regocijarse con sus fiestas, zambras y recreaciones; y para decir verdad, la conversión fue por fuerza contra lo capitulado por los reyes católicos cuando el rey Abdilehi les entregó esta ciudad; y mientras sus altezas vivieron, no hallo yo, con todos mis años, que se tratase de quitárselo... Nuestro hábito cuanto á las mujeres no es de moros; es traje de provincia como en Castilla y en otras partes se usa diferenciarse las gentes en tocados, en sayas y calzados. . Nuestras bodas, zambras y regocijos, y los placeres de que usamos, no impide nada al ser cristianos... Veamos, señor: hacernos tener las puertas de las casas abiertas ¿̇de qué sirve? Libertad se da á los ladrones para que hurten, á los livianos para que se atrevan á las mujeres... ¿podrâse averiguar que los baños se hacen por cerimonia? No por cierto... Pues vamos á la lengua arábiga, que es el mayor inconveniente de todos. ¿Cómo se ha de quitar á las gentes su lengua natural, con que nacieron y se criaron? Los egipcios, surianos, malteses y otras gentes cristianas, en arábigo hablan, leen y escriben, y son cristianos como nosotros... ${ }^{13}$

Tras la condescendencia táctica de la primera época, en 1567 ya las circunstancias habian cambiado de manera sensible y las ponderadas razones del letrado morisco no surtieron el efecto apetecido, resultando asimismo estériles otras varias gestiones en igual sentido, cuales fueron, por ejemplo, las del marqués de Mondéjar y las del caballero Juan Enríquez. A este propósito, ha de tenerse en cuenta un posible argumento por parte de los gobernantes aunque no parezca formulado de manera concreta: ¿Cómo podían considerarse típicas de una provincia o región costumbres practicadas por grupos de moriscos, a veces muy alejados entre sí? Lógicamente se les suponían raíces más antiguas y profundas.

De todos modos, la suerte estaba ya echada y los letrados de la Chancillería, así como ciertos grupos de presión, habían conseguido ya que la decisión de suprimir definitivamente la estructura

${ }^{13}$ El texto del Memorial puede verse en MArmol, op. cit., pp. 163-165, reproducido por García Arenal, precedido de una nota introductoria, en Los moriscos, pp. 47-56. Cf., también, K. GARRARD, "The original Memorial of Don Francisco Núñez Muley", Atlante, 2 (1956), pp. 168-226. Para las causas mediatas e inmediatas de la sublevación, puede verse CARO BAROJA, Los moriscos, pp. 101-171, debiendo añadirse otra de carácter económico, cual fue la decadencia de la industria de la seda, acertadamente estudiada por $\mathrm{K}$. GARRARD, "La industria sedera granadina y su conexión con el levantamiento de las Alpujarras (1568-1571)", MEAH, 5 (1956), 73-104. 
social representada por los moriscos apareciese como irreductible y sin la menor posibilidad de suspensión o aplazamiento. No les quedaba pues, más alternativa que la sumisión o la guerra, como resultado de su pertinaz resistencia a integrarse y de la floja e inadecuada voluntad de asimilarlos por parte de los vencedores: ¡Triste final de una convivencia de espaldas entre ambas comunidades!

\section{LA VIOLENCIA DEL CHOQUE}

El camino elegido fue el de la guerra dura, tenaz y sangrienta, que se prolongó por espacio de tres años (1568-1571) y en la que fue preciso el temple de capitanes tan expertos como el marqués de Mondéjar, el marqués de los Vélez don Luis Fajardo, el duque de Sesa don Gonzalo Fernández de Córdoba - el futuro Gran Capitán - y el propio don Juan de Austria, llegado a Granada el 13 de abril de 1569 , por orden de Felipe II, como jefe supremo de las tropas cristianas. No mucho después era llamado a la Corte el marqués de Mondéjar, desvaneciéndose con su partida las últimas esperanzas de los sublevados moriscos, que habían fijado su centro de operaciones en los abruptos parajes de Las Alpujarras ${ }^{14}$.

Durante la contienda fue tomando cuerpo, sobre todo en el ánimo del circunspecto y sagaz Pedro de Deza, la idea de prevenir nuevas revueltas desterrando del reino de Granada a todos los moriscos en él afincados. Tal medida, que en parte ya se había ido aplicando con cierta improvisación al compás de la guerra, fue abiertamente censurada por relevantes personalidades, debido a las funestas consecuencias que podría provocar, sobre todo en el aspecto económico, como así ocurrió; sin embargo, la nueva orientación, fijada ya por los Reyes Católicos, de que al Estado correspondía también preservar la unidad religiosa como parte integrante de la unidad político-social de la nación española - de aquí la expulsión de la comunidad judía - , se considera ya principio de aplicación normal en el siglo XVI y causa justificante de la Inquisición, cuya actuación frente al problema morisco - hoy mejor conocida - resultó prácticamente estéril, no obstante su amplitud e intensidad ${ }^{15}$.

\footnotetext{
${ }^{14}$ Para un resumen de las vicisitudes de esta guerra, puede verse mi monografía El morisco granadino Alonso del Castillo, Granada, 1965, pp. 79-120, aparte de las historias contemporáneas de Mármol y Hurtado de Mendoza ya citadas.

${ }_{15}$ En cuanto a los moriscos y la Inquisición, tema sobre el que mucho se ha
} 
Así, pues, las "sacas" de moriscos del reino de Granada hacia la Baja Andalucía, Extremadura y, sobre todo, las dos Castillas, donde antes apenas existía el problema morisco, se fueron sucediendo de manera inexorable y conforme a una planificación sistemática según sus zonas de origen, pero en los lugares de su nueva residencia plantearían continuos problemas y constituirían un grupo desarraigado y sin medios de vida, que seguiría expresándose en "algarabía" y manteniendo tenazmente sus costumbres, actitud que con frecuencia les acarrearía la humillación, el aislamiento e incluso la persecución por parte de los cristianos ${ }^{16}$.

INTENTO DE SUPERVIVENCIA

Aunque en la disposición relativa a su destierro del reino de Granada se vieron también incluidos los moriscos que no se habían sublevado, algunos, sobre todo de cierta posición y cultura, no se vieron afectados en la práctica por tal medida, sin duda, en atención a su probada fidelidad a los servicios prestados antes y durante la guerra y a los que aún podrían prestar en el futuro; éste sería el caso, entre otros, de Alonso del Castillo y Miguel de Luna, a los que posteriormente habré de referirme de manera especial.

Pero es importante recordar que entre los moriscos de Aragón, Valencia y Granada - los tres reinos de mayor población islámica - existía una diferencia fundamental, pues mientras los granadinos eran de condición libre y de espíritu emprendedor, los aragoneses y valencianos estaban sometidos a un régimen señorial más bien duro. Es posible que a esto se deba el que fuese precisamente en Granada donde se dieron algunos casos de asimilación entre los moriscos más cultos y acomodados e incluso entre miembros de la nobleza granadina, como los Granadas y Venegas.

Tal vez por esta especial condición del morisco granadino, va a producirse aquí, y en este momento histórico, un fenómeno extremadamente curioso, aunque, en cierta medida, lógico y natural, al menos en su etapa inicial. Perdida su estructura política con la reconquista de la ciudad por los Reyes Católicos e incumplidas luego las capitulaciones que ellos les habían otorgado,

escrito ya, citaré sólo el interesante capítulo que le dedica Cardaillac en Moriscos y cristionos. . . pp. 85-118, con abundante bibliografia.

${ }^{16}$ Acerca de los moriscos desterrados a Castilla, cf. BERNARD VINCENT, "L'expulsion de morisques du royaume de Grenade et leur repartition en Castille (1570-1571)", $M C V, 6$ (1970), 210-246. 
los moriscos granadinos acababan de comprobar la inutilidad de la defensa de sus nombres, lengua, traje y costumbres hecha por Núñez Muley; ante la inmediata perspectiva de ver definitivamente suprimida su estructura social, cultural y religiosa, no se resignan a desaparecer por completo, y algunos - de los más instruidos y menos sospechosos - intentan salvar al menos una parte de su herencia espiritual mediante la incorporación de algunas de sus doctrinas a lo que, por la nueva unidad política y religiosa, iba a ser patrimonio común del pueblo español.

La aludida incorporación tuvo, como primer paso, el descubrimiento de una caja con diversas reliquias y un pergamino escrito al derribar la antigua Torre Vieja o Torre Turpiana, minarete de la mezquita mayor de Granada, para construir la tercera nave de la actual catedral en 1588 ; pero el escenario principal de los hechos fue la colina de Valparaíso - muy pronto llamada del Sacromonte - , que se eleva frente a las laderas del Generalife, dejando en medio la silenciosa cuenca del Darro ${ }^{17}$.

El vehículo de la aludida incorporación fueron los llamados "libros plúmbeos", cuya aparición sucesiva a partir de 1595 dio origen a una larga controversia que apasionó vivamente a los granadinos, a muchos españoles e incluso a nuestros reyes, con los más altos organismos del Estado, haciendo correr mucha tinta desde finales del siglo XVI y durante todo el siglo XVII, aun después de haber sido condenados como apócrifos por el papa Inocencio XI en $1682^{18}$.

En efecto, la orientación que da cierta unidad formal a los veintidós libros hallados en las cuevas de Valparaíso, no obstante

${ }^{17}$ Cf. Miguel Jose HagerTy, "Los libros plúmbeos y la fundación de la insigne iglesia colegial del Sacromonte", en la obra miscelánea titulada La Abadía del Sacromonte. Exposición artístico-documental. Estudios sobre su significación y origenes, Granada, 1974, pp. 18-33, pp. 20-170; ZóT ICo Ro. yo, Reliquias martiriales y escudo del Sacromonte, Granada, 1960, pp. 20 170 , sensiblemente ingenuo y falto de crítica.

${ }^{18} \mathrm{La}$ bibliografía tanto impresa como manuscrita es abundantísima. Para lo conservado en el Sacromonte, aparte los legajos de su actual Archivo, cf. HAGERTY, art. cit., pp. 73-82. Para la historia de este problema, véanse JosÉ GODOY ALCÁNTARA, Historia crítica de los falsos cronicones, Madrid, 1869; THOMAS D. KENDRICK, Saint James in Spain, London, 1960; CARLOS ALONso, Los apócrifos del Sacromonte: estudio histórico, Valladolid, 1979, que completa todo lo anterior, utilizando nuevas fuentes españolas y extranjeras, pero, sobre todo, las conservadas en la Biblioteca y Archivo Vaticanos. Tanto del pergamino de la Torre Turpiana como de los libros plúmbeos me ocupé también en El morisco granadino Alonso del Castillo, pp. 177-195 y 197-232, respectivamente. 
su variedad temática, es una especie de sincretismo de doctrinas islámicas y cristianas, un pretendido credo común que resultase igualmente aceptable para los seguidores de ambas religiones, incluyendo en él algunas de las doctrinas musulmanas que menos pudiesen chocar a los cristianos y viceversa ${ }^{19}$. Así, en ese conjunto de elementos sensiblemente heterogéneos, se admite la supremacía del Papa, la doctrina de la inmaculada concepción de la Virgen, la venida del apóstol Santiago a España, etc.; pero todo ello sobre un fondo monoteísta en el que Jesucristo no aparece como hijo de Dios, sino como una manifestación del Espíritu de Dios. Junto a estas doctrinas fundamentales se incluye toda una serie de preceptos, consejos e insinuaciones que delatan con toda claridad su procedencia: se dice, por ejemplo, que el cáliz en la misa es para el agua "cambiada" - a fin de no mencionar el vino --; antes de consagrar, el sacerdote debía lavarse no sólo las manos, sino también la boca y la cara (lo que nos recuerda las abluciones del Islam); se aconseja a las mujeres que lleven el velo en las vida ordinaria, etc. Hay, sin embargo, dos cuestiones a las que ni siquiera se alude, como son la monogamia y el culto de las imágenes.

Mas, aparte este sincretismo doctrinal, hay en los libros otro aspecto decisivo para descubrir el origen de los mismos, aspecto del mayor alcance desde el punto de vista religioso y que podriamos llamar de preferencia: tras la crucifixión de Jesús, Dios habría preferido a los árabes y rechazado a los judíos, habiendo elegido también la lengua árabe como vehículo para la revelación final de su divina voluntad. Aunque a la sazón los turcos habían asumido la dirección política del mundo islámico, los árabes volverían a recobrar su hegemonía y ellos serían justamente los protagonistas de una nueva revelación de la Ley. El último concilio general de la Iglesia, esperado por los árabes y que se celebraría en la isla de Chipre, iría seguido de la conversión de todo el mundo al cristianismo y, por fin, llegaría la época mesiánica para los moriscos de España, ya que, por su esfuerzo y "por la gracia del cielo", la historia del cristianismo habría alcanzado su máximo esplendor y todos rendirían homenaje de pleitesía a la raza morisca.

${ }^{19}$ Sobre esto pueden verse mis dos siguientes artículos: "El Sacromonte, punto de confluencia doctrinal entre el islam y la cristiandad", La Abadía del Sacromonte, pp. 34-40; "Un intento de sincretismo islámico-cristiano: Los libros plúmbeos de Granada", Actas del Segundo Congreso Internacional de estudios sobre las culturas del Mediterráneo Occidental (Barcelona, 1978), 131-142. 
Como observa Kendrick ${ }^{20}$, tal vez el propósito inicial de los moriscos que tramaron esta singular aventura, fuera simplemente exaltar a Granada en santidad y antigüedad sobre todas las ciudades de España; pero la enorme sensación despertada por los primeros hallazgos les hizo concebir sin duda un proyecto más ambicioso, cual sería el de asombrar, no sólo a España, sino incluso al mundo islámico y a toda la cristiandad; semejante proyecto parece desprenderse del contenido doctrinal de los libros, estudiado en relación con su aparición sucesiva.

Es indudable que, según la premeditada concepción de los moriscos implicados en este asunto, con el impacto de tan sensacionales descubrimientos - pues se pretendía que los libros eran del siglo I de nuestra era - , Granada cerraba su etapa de transición de ciudad "mora" a ciudad cristiana, aunque asumiendo su tradición morisca, y pretendía dar respuesta a unas exigencias que pesaban igualmente sobre vencedores y vencidos, si bien en distinta medida y por razones muy diferentes: para los primeros el vacío apremiante de una ciudad sin mártires y sin historia eclesiástica durante los ocho siglos de dominación musulmana, vacío que la colocaba en posición de cierta inferioridad con respecto a otras ciudades españolas y extranjeras más afortunadas en este aspecto, al que entonces tanta importancia se concedía en todo el orbe cristiano; en cuanto a los segundos, al lógico afán de salvar algunos elementos de su rica civilización, ya en irreversible agonía, se sumaba el deseo de paliar ante el pueblo español la terrible sensación que en él había producido la reciente y feroz sublevación de la Alpujarra, sin olvidar la ingenua utopía de conseguir la rehabilitación de la raza morisca y su apoteosis final, utopía difícilmente conciliable con la dura realidad de su vida en a quellos momentos.

\section{LAORIGINALIDAD DEL INTENTO}

Trazado este indispensable panorama histórico, aquí los libros plúmbeos me interesan en cuanto representan el último y más amplio testimonio escrito en árabe de la civilización hispanomusulmana, ya en su ocaso durante esta penosa y tan discutida etapa morisca. Mas, para enfocar adecuadamente el aspecto lingüístico de los libros, no se puede prescindir de los objetivos perseguidos en su elaboración, ni tampoco del contexto religioso, social y cultural

${ }^{20}$ Saint James in Spain, pp. 141-142. 
en que ésta se produce. Si no existiesen tales objetivos, dichos textos constituirían, logicamente, un fiel reflejo del árabe literal de los moriscos de esta época, árabe sensiblemente depauperado ya, influido por su propio dialecto granadino e incluso por ciertas estructuras del castellano, como ocurre, por ejemplo, en la Doctrina christiana del obispo de Guadix - y luego arzobispo de Valencia - don Martín de Ayala, traducida al árabe por el clérigo beneficiado Bartolomé Dorador para instrucción de los moriscos y que ha sido estudiada por mi discípula $\mathbf{M}^{\mathbf{a}}$. Paz Torres Palomo ${ }^{21}$. Pero también podría esperarse que los textos en cuestión estuvieran en árabe dialectal granadino, para su mejor comprensión por todos los moriscos que aún permanecían en la región después de las "sacas" anteriormente aludidas, muchos de los cuales no conocían ya el árabe literal o clásico; mas esto, por desgracia para nosotros, tampoco es así.

Lo que realmente pretendían los autores de los libros, en consonancia con su finalidad doctrinal, era hacer creer que la redacción de los mismos había tenido lugar en Jerusalén durante el siglo I de la era cristiana, viviendo aún la Virgen y los apóstoles, y que los discípulos de Santiago y primeros evangelizadores de la Hispania romana eran de origen árabe, sin duda para contrarrestar - según hemos adelantado ya - el penoso efecto producido en los cristianos por la guerra de las Alpujarras, recientemente concluida.

Por tal motivo se esfuerzan en que tanto el vocabulario como la estructura de la frase evoque aquellos primeros tiempos del cristianismo en Oriente; mas esto los lleva, en ocasiones, a la hipercorrección ortográfica, por su afán arcaizante, y a cierta ambigüedad y fluctuación lexicográfica, sin olvidar, además, que, tratándose de moriscos relativamente cultos, intentaban escribir en árabe elegante. De ahí que, a pesar de ciertos reflejos del árabe dialectal granadino, a los que luego he de aludir, su influencia no es tan marcada que nos permita valorar realmente el estado de este dialecto por aquel entonces, en relación, por ejemplo, con los inapreciables textos de fray Pedro de Alcalá22.

${ }^{21}$ Bartolomé Dorador y el árabe dialectal andaluz, extracto de tesis doctoral, Universidad de Granada, 1971.

${ }^{22}$ Arte para ligeramente saber la lengua arávica y vocabulista-arávigo en letra castellana, Granada, 1505, reeditada por P. de LAGARde, Petri Hispani de lingua arabica libri duo, Gottingae, 1883; reproducción fotomecánica de Otto Zeller, Osnabrück, 1971 y reprod. en facsímil de la edición príncipe por la Hispanic Society of America en 1928, de lectura incómoda por la excesiva reducción del original. 
Mas, a pesar de la aceptable cultura de los falsificadores y de sus evidentes esfuerzos para alcanzar los objetivos propuestos, el texto árabe de los libros resulta de una estructura sencilla y casi elemental, sin muestras de elegancia en su estilo ni apreciable valor de pensamiento: además, no pueden evitar que en los mismos se reflejen fenómenos que denotan ya un cierto desconocimiento de la gramática, o determinadas influencias del árabe dialectal granadino. Recordemos, entre otros aspectos, ciertos cambios que afectan a la morfología de algunas palabras, concordancias defectuosas, uso indebido de los casos, elisión de consonantes, cambio de sílabas breves en largas y al contrario, o de una consonante por otra (v. gr.: $t$ por $d$, $d$ por $d$, $s$ por $s, k$ por $q$, y viceversa), uso prácticamente normal de la terminación in para el nominativo de los plurales externos o sanos, cuando aquélla es propia de los casos directo e indirecto del mismo número. Por carecer de vocales, salvo en algunas sílabas largas, no pueden formularse conclusiones acerca de la influencia dialectal en la pronunciación de los moriscos.

De todos modos, y a pesar de las anomalías señaladas, que suelen darse en textos de árabe decadente o con influencias dialectales, tal vez sólo en Granada fuese entonces posible la redacción de tales libros, siendo ésta una prueba más - entre otras - de que aquí la lengua árabe se cultivaba todavía, al menos por un grupo de moriscos de cierta cultura, lo que acaso explique la ausencia de textos aljamiados escritos en la región. Por el contrario, en otras zonas de la Península los moriscos habían perdido ya el dominio de la lengua árabe, teniendo que acudir a las traducciones para no olvidar los preceptos de su religión, como se desprende, por ejemplo, del pasaje manuscrito ofrecido por mi buen amigo L. P. Harvey ${ }^{23}$ : "I ansí çelosos de mantener el adín del alislem, reconociendo esta isla estar tan escura a causa del perdimiento de los sabios. . . Los que oy biben y por tiempos bibirán por gracia de Allah, $t a^{c} \tilde{a} l \ddot{a}$, an perdido las luzes y escuelas y el ' $a r a b \bar{\imath}$ ".

Ese desconocimiento de la lengua árabe fue también lo que determinó el nacimiento de la literatura aljamiada, como subraya mi maestro García Gómez en las siguientes palabras: "El primer motivo es desde luego religioso. La sagrada lengua en que el Corán fue revelado está en indisoluble unión con la escritura, que por ello pasa a ser también sagrada, y es natural que si los moriscos habían perdido el dominio de la lengua, quisieran por lo menos apegarse

23 "El mancebo de Arévalo y la literatura aljamiada", Actas del Coloquio Internacional sobre literatura aljamiada y morisca, Madrid, 1978, p. 25. 
al alifato árabe. Pero como resulta indudable que al conocer la lengua española conocían asimismo el alfabeto latino, es lógico pensar que, a más de los motivos religiosos, entraban en juego otros profanos, como el hacer que sus escritos fuesen «crípticos»: estuviesen en «cifras». Si esto no sucede en todos los casos, hubo de ocurrir en bastantes: la escritura, en todo caso, «distanciaba» al morisco del mundo hostil en que había de vivir, creaba para él una «muralla psicológica»"24.

La originalidad formal de los libros plúmbeos radica precisamente en la forma especial de su grafía árabe, en la que sus autores cifraban la esperanza de que fuesen considerados como verdaderos documentos antiguos; pero, además, no puede descartarse en aquéllos la oculta intención de que sus textos resultasen asimismo crípticos para los arabistas de su tiempo, asegurándose con ello la primacía en la traducción e interpretación de los mismos, extremo que los hechos posteriores vendrían a confirmar, según luego veremos.

Las láminas de plomo, que en número diverso formaban las hojas de estos libros, eran muy delgadas, de forma circular y a veces aparecían ensartadas en un hilo también de plomo. Escritas con fino buril por ambas caras, en ellas se empleaban, en ocasiones, combinaciones de círculos y triángulos entrelazados en forma de estrella - que será el escudo del Sacromonte - , empleando en la escritura un tipo de caracteres que los moriscos llamaron "salomónicos", pero que en realidad son los mismos caracteres árabes ordinarios con ciertas modificaciones y forma preponderantemente angular, que, en apariencia al menos, les da un aspecto de mayor antigüedad. Esta especie de hojas, agrupadas según ciertos temas doctrinales y envueltas en una cubierta de plomo, sobre la que, de ordinario, aparecía grabado su título en tosco latín - similar al del pergamino de la Torre Turpiana - , constituyen los llamados libros o láminas plúmbeas ${ }^{25}$.

Sabido es que las consonantes del alifato árabe, salvo algunas excepciones, tienen cuatro formas parcialmente diferentes, según aparezcan aisladas u ocupen en un vocablo posición inicial, medial o final; por el contrario, en la grafía de los libros plúmbeos, aparte su carácter angular ya señalado y, a veces, su distinta posición respecto a la línea de escritura, cada consonante presenta, de

${ }^{24}$ E. GARCía GÓMEZ, "Palabras pronunciadas en la sesión de clausura" del Coloquio citado en la nota anterior, pp. 501-502.

25 D. Cabanelas, El morisco granadino..., pp. 200-201. 
ordinario, una forma única, que es la aislada, salvo ligeras modificaciones para algunas de ellas en posición inicial, medial o final.

En la lámina I pueden observarse ésas y otras diferencias entre el alifato árabe normal y los caracteres "salomónicos" empleados por los moriscos, que sepamos, sólo en estos libros. Se ha de tener en cuenta, además, que la forma de una consonante en cualquiera de sus posiciones donde esté sustituida por el signo $=$, es igual a la forma de la misma en la columna vertical donde ésta aparezca; por ello, y de acuerdo con la tendencia de los moriscos a emplear en estos libros una forma única para cada letra, se puede comprobar cómo el signo = abunda mucho más en el alifato de los caracteres "salomónicos".

Pero a esta dificultad, al menos inicial, originada por la forma especial de las consonantes, viene a sumarse otra tal vez de mayor trascendencia, cual es la frecuente omisión de los puntos característicos de muchas de esas consonantes - como si de escritura cúfica se tratase - , dándose el caso de que un simple trazo, sin punto alguno, puede representar hasta cinco letras distintas, extremo fácilmente comprobable en ambos alifatos de la lámina $I$.

Esta dificultad fue rápidamente valorada por un hombre tan experto en temas bíblicos y lenguas orientales como Benito Arias Montano, por cierto uno de los pocos clarividentes adversarios que desde el principio tuvieron el pergamino y los libros plúmbeos y que expuso al arzobispo don Pedro de Castro, con tanta claridad como delicadeza, los argumentos más decisivos contra la autenticidad de los descubrimientos granadinos, según se desprende de la nutrida correspondencia entre ambos y de la cual me ocupé en otro lugar $^{26}$.

En una de las cartas que, inadvertidamente, no incluí en mi trabajo ${ }^{27}$ y cuyo extracto nos ofrece el P. Carlos Alonso en su reciente y ya citado libro ${ }^{28}$, Arias Montano contesta el 10 de noviembre de 1596 a otra de don Pedro de Castro relativa a la posible traducción de los nueve libros plúmbeos que hasta entonces se habían descubierto. Tras breves consideraciones sobre su for mación en lenguas orientales, indica al arzobispo que el problema de la versión de los textos granadinos no radica tanto en que

26 "Arias Montano y los libros plúmbeos de Granada", MEAH, 18/19 (1969-70), 7-41.

${ }^{27}$ Por hallarse en el leg. II del Archivo del Sacromonte y no en el IV, donde se encontraban todas las demás cartas que entonces publiquế.

${ }^{28}$ Los a pócrifos del Sacromonte, pp. 133-134, a base de Egerton, vol. 442 (fols. 109r-110v) del British Museum. 


\begin{tabular}{|c|c|c|c|c|c|c|c|}
\hline \multicolumn{4}{|c|}{ ALIFATO ĀRABE NORMAL } & \multicolumn{4}{|c|}{ CARACTERES "SALOMÓNICOS" } \\
\hline Aislada & Inicial & Medial & Final & Aislada & Inicial & Medial & Final \\
\hline 1 & $=$ & $=$ & $l$ & & $=$ & $=$ & $=$ \\
\hline 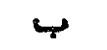 & بـ & $\rightarrow$ & $\leftarrow$ & + & $=$ & $=$ & $=$ \\
\hline تـ & ت & $\ddot{~}$ & مست & $\ddot{i}$ & $=$ & $=$ & $=$ \\
\hline ت & 3 & $\dot{~}$ & $\ddot{-}$ & $\dot{i-}$ & $=$ & $=$ & $=$ \\
\hline 乙 & $\rightarrow$ & $\rightarrow$ & $\tau$ & & $=$ & $=$ & $=$ \\
\hline z & $\rightarrow$ & $\leadsto$ & r & $\rightarrow$ & $=$ & $=$ & $=$ \\
\hline$\dot{c}$ & $\dot{-}$ & $\dot{x}$ & $\dot{c}$ & & $=$ & $=$ & $=$ \\
\hline 3 & $=$ & $>$ & $=$ & & $=$ & $=$ & $=$ \\
\hline$j$ & $=$ & $j$ & $=$ & & $=$ & $=$ & $=$ \\
\hline$\jmath$ & $=$ & 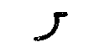 & $=$ & & $=$ & $=$ & $=$ \\
\hline j & $=$ & $j$ & $=$ & & $=$ & $=$ & $=$ \\
\hline س & س & س & س & -1 & $\frac{\text { II }}{1}$ & $=$ & $m$ \\
\hline نُّ & شَ & ش & شَّ & & $=$ & $=$ & $=$ \\
\hline$\infty$ & $\varnothing$ & $\infty$ & $\sim A$ & & ـحس & $=$ & ح \\
\hline$\dot{C D}$ & $\dot{\phi}$ & $\dot{\theta}$ & $\dot{\omega}$ & & هــ & $=$ & \\
\hline$b$ & $b$ & ba & $b$ & t & $=$ & $=$ & $=$ \\
\hline$b$ & $b$ & b & $\dot{~}$ & $t$ & $=$ & $=$ & $=$ \\
\hline$\varepsilon$ & $\mathcal{c}$ & $z$ & $E$ & $\Gamma$ & $=$ & $\rightarrow$ & \\
\hline$\dot{\varepsilon}$ & $\dot{\Sigma}$ & $\dot{\boldsymbol{x}}$ & $\dot{z}$ & $\Sigma$ & $=$ & $\dot{\nabla}$ & \\
\hline$\dot{9}$ & ف & $\dot{\theta}$ & فو & $\dot{q}$ & $=$ & $=$ & $=$ \\
\hline ق & $\ddot{g}$ & $\ddot{\ell}$ & ت & & $=$ & $=$ & $=$ \\
\hline sf & 5 & 5 & d) & & $=$ & $=$ & $=$ \\
\hline$J$ & $J$ & 1 & $J$ & & 1 & $=$ & \\
\hline ر & هـ & $a$ & م & & $\frac{a}{i}$ & $=$ & \\
\hline $\mathcal{U}$ & j & $i$ & ש & & 1 & $=$ & 与 \\
\hline $\mathbf{0}$ & هـ & $t$ & $\Delta$ & 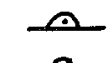 & $=$ & $=$ & $\Delta$ \\
\hline 9 & $=$ & $y$ & 9 & & $=$ & $=$ & $=$ \\
\hline ي & يـ & + & كب & 5 & بـ & $=$ & 5 \\
\hline$y^{\circ}$ & $=$ & $=$ & $\begin{array}{l}= \\
\ddot{4}\end{array}$ & $\frac{x v}{\ddot{n}}$ & $=$ & $=$ & $\begin{array}{l}= \\
\ddot{A}\end{array}$ \\
\hline
\end{tabular}


Comienzo del Kitāb qawā' id l-Din, "Libro de los fundamentos de la Religión". Manuscrito A. 1. Granada (Sacromonte).

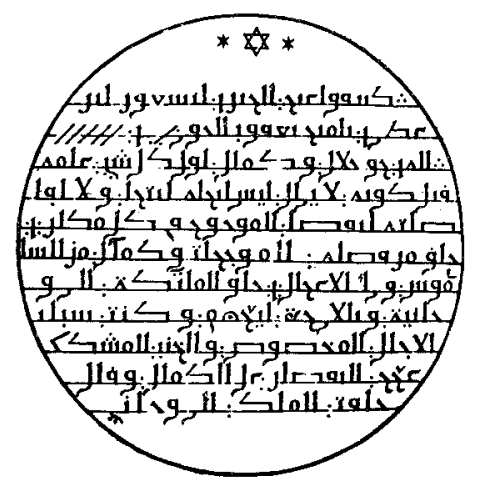

TRANSCRIPCIÓN PALEOCRAFICA

1

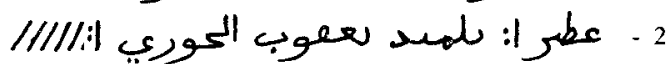

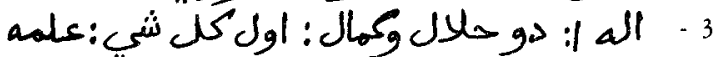

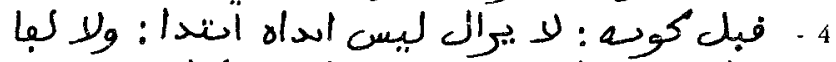

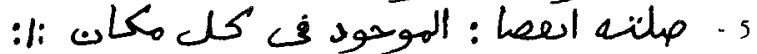

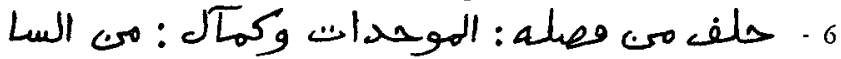

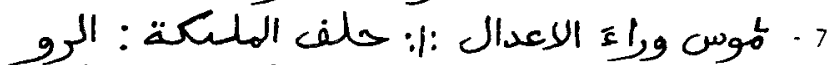

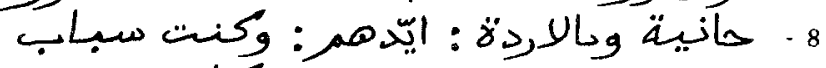

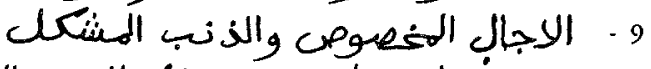
10 11-

TRANSCRIPCIÓN CORREGIDA

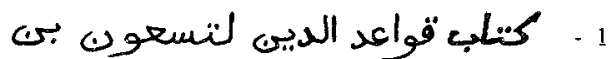

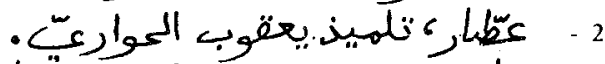

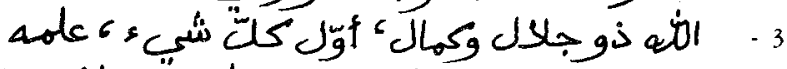

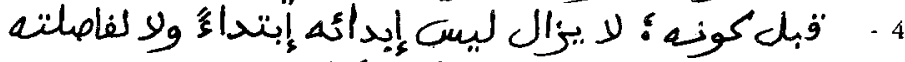

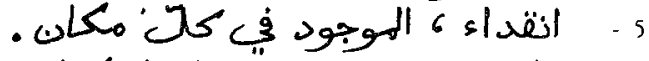

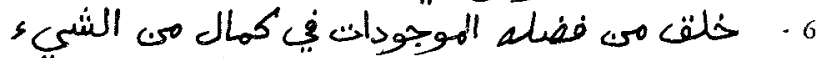

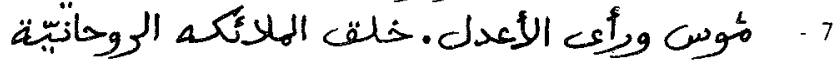

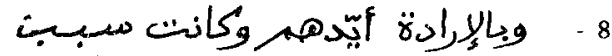

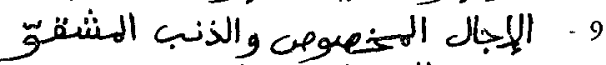

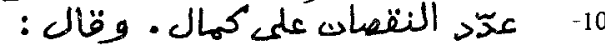

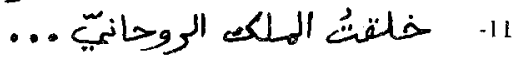

Lámina II 
aquéllos carezcan de "judas" o "haracas", es decir, de vocales"29, o que en realidad no representaría una dificultad para los entendidos, sino en la falta de los puntos sustanciales de las consonantes ${ }^{30}$; por ello desafía y se compromete a poner en aprieto a cuatro traductores diversos a base del pergamino, del cual posee una copia, "y ninguno me podría huir con maña". Concluye, pues, Arias Montano que, "si los nuebe libros están en la mesma forma, ternán o darán bien que hacer a diversos intérpretes".

Estas últimas palabras del sabio orientalista resultaron en verdad casi proféticas, según luego veremos; pero antes quiero presentar en la lámina II una simple muestra de cuanto llevo dicho respecto a la grafía árabe de los libros. Para ello reproduzco una de las ilustraciones ofrecidas en mi monografía sobre El morisco granadino Alonso del Castillo, que es la cara a de la primera lámina del Kitâb qawâa'id al-din o "Libro de los fundamentos de la religión"31. Primeramente ofrezco la transcripción paleográfica de sus once líneas, donde puede observarse la carencia de puntos diacríticos en la mayoría de las palabras, así como las restantes anomalías anteriormente señaladas ${ }^{32}$. Seguidamente presento la transcripción que estimo correcta, con la puntuación adecuada, sin que en modo alguno se vea reflejado el elegante estilo árabe pretendido por sus autores.

He aquí ahora la traducción española del fragmento transcrito:

Libro de los fundamentos de la religión por Tesifón ${ }^{33}$ ibn 'Attär, discípulo de Santiago (Yac $q \bar{u} b$ ) apóstol.

${ }^{29}$ Se trata de los vocablos árabes - castellanizados por los moriscossuklas (del árabe šakkal 'vocalizar un texto') y haraqa ('moción' o vocal). Es posible que en la transcripción del $\mathrm{P}$. Alonso se haya deslizado una ligera errata, perfectamente explicable, al leer "judas" en vez de "juclas". En los escritos de los moriscos he hallado en más de una ocasión el verbo latinizado xuclare y axuclare, con la misma significación de vocalizar un texto árabe.

${ }^{30}$ En la transcripción del $\mathrm{P}$. Alonso se dice - no sé si por defecto de lectura o porque así aparece en la carta - la falta de las puntas sustanciales de las consonantes (el subrayado es nuestro).

${ }^{31}$ Tomada del manuscrito del Sacromonte que lleva por título Copias vorradores de los libros plúmbeos árabes, Granada, 1607, de Alonso del Castillo y Miguel de Luna, que tiene la signatura ms. A. l. en el nuevo y ya citado Catálogo de HAGERTY, La A badia del Sacromonte, p. 74.

${ }^{32}$ La puntuación que se ofrece en estos libros presenta tres formas: :|, que a veces representa una coma; :, equivalente a punto y seguido, punto y coma o simplemente coma; y :|: que significa punto y aparte. De todos modos, este sistema de puntuación no responde a la estructura lógica del texto en la mayoría de las ocasiones.

${ }^{33}$ Es de señalar la forma Tisi $^{c} \bar{u} n$ en que aparece transcrito el nombre Tesifón, con el cambio de fa por ${ }^{c} a y n$. 
Dios es grande y perfecto, el primero de todos los seres, que Él conoció ya antes de que existiesen; su origen carece de principio y su existencia no tiene fin; es omnipotente. Por su gracia creó de la nada ${ }^{34}$ cuanto existe, con perfección, y vio que era adecuado. Creó a los ángeles espirituales y les otorgó el libre albedrio, que fue la causa de su propio destierro, considerándose este abominable pecado como mengua de su perfección. Y dijo: creé al ángel espiritual. .

\section{CONSECUENCIAS DE LA INNOVACIÓN}

Por razones obvias, el grupo de moriscos implicado en este asunto debió de ser muy reducido a fin de guardar mejor el secreto; sin embargo, en la etapa inicial del proyecto dos hombres aparecen como sospechosos: Castillo "el viejo", padre del licenciado Alonso del Castillo, y El-Meriní, que "presumía de muy leído y tenía muchos papeles árabes"; éste murió durante el primer año de la sublevación de 1568 , dejando una hija que más tarde se casó con un tal "Mendoça el Seis", morisco también. La hija del Meriní entregó luego los papeles de su padre al morisco Miguel de Luna ${ }^{35}$.

En las cartas que acabo de citar, Luis de Mármol aconsejaba a don Pedro de Castro que, en relación con los descubrimientos granadinos, y una vez fallecidos El-Meriníy Castillo el viejo, convenía interrogase a los moriscos Miguel de Luna y Alonso del Castillo ${ }^{36}$. En efecto, por toda una serie de indicios que no voy a exponer aquí, ambos fueron, probablemente, los dos elementos clave en la ejecución del proyecto, colaborando incluso en la redacción de algunos de los libros, como luego ìo harían en su traducción ${ }^{37}$. Es indudable que en ambos concurrían unas circunstancias excepcionalmente propicias para intentar tan audaz y arriesgada aven-

${ }^{34}$ Como puede verse en la lámina II, el texto árabe dice al-šay'malüs, esta última palabra con el lãm sobrevolado no visto por los traductores, quienes han transcrito el conjunto simplemente por el vocablo xamuz, con la significación de 'cosa inexistente', 'nada'. ¿Será malüs una palabra dialectal formada por $m \bar{a}$ y laysa, cosa 'que no existe'?

${ }_{35}$ Véanse las dos interesantes cartas dirigidas por Luis del Mármol a don Pedro de Castro, que le había pedido opinión sobre este asunto; cartas conservadas en el Archivo del Sacromonte, leg. IV, parte I ${ }^{\mathrm{a}}$, ff. $17 \mathrm{r}-22 \mathrm{r}$ y 23 , y que publiqué en El morisco granadino..., pp. 185-189 y 189-191, respectivamente.

${ }^{36}$ Del primero traté en "Cartas del morisco Miguel de Luna", MEAH, 14/15 (1965-1966), 31-47, y en varios pasajes de El morisco granadino, sobre todo, pp. 182-184, 214-217 y 229-231.

${ }^{37}$ Para sus versiones conservadas en el Sacromonte, cf. el Catálogo de HaA. GERTY, La Abadía del Sacromonte, pp. 74-82. 
tura, pues, a más de disfrutar de la confianza oficial por su empleo de traductores, ejercían la medicina y estaban exentos, al menos en apariencia, de todo fanatismo, aceptando la situación tal como se presentaba y procurando sacar de ella el mejor partido posible. "Superiores en ilustración a los suyos - escribe Godoy Alcántara ${ }^{88}-$, comprendieron que su causa estaba perdida y que el mayor servicio que para mitigar su desventura podían prestarles, era secundar la obra de pacificación y concordia por medio de la infusión de nuevas doctrinas religiosas que harían superable la barrera divisoria de ambos pueblos".

Aquí, sin embargo, quiero subrayar tan sólo dos aspectos que interesan a mi actual propósito. El primero se refiere a la opinión expresada - que no creída - por ambos moriscos respecto a los libros. En el manuscrito 6637 de la Biblioteca Nacional de Madrid existe una copia de las versiones de los libros, seguida de una defensa de los mismos dirigida al rey, tal vez por don Pedro de Castro, aunque por estar acéfala desconocemos tanto la fecha como el nombre del autor. En esta defensa se alude a un intérprete - cuyo nombre se omite - que había censurado ante el monarca la antigüedad de los libros, y en ella se dice lo siguiente sobre Alonso del Castillo y Miguel de Luna ${ }^{39}$ :

Los que mejor los leyeron y entendieron fue el licenciado Alonso del Castillo y Miguel de Luna, vecinos de Granada, intérpretes de Su Majestad, que sabían por cierto bien la lengua árabe como los orientales. Éstos, examinados con juramento, dixeron de la elegancia y grandeza del estilo y antigüedad de los libros. El licenciado Alonso del Castillo dice que los libros están escritos en lengua árabe antigua [f. 173v] preceptiva y que tienen muchos vocablos árabes antiquísimos, inusitados en la lengua moderna, que no se hallan en los diccionarios árabes, y que tienen frases y elegancia antiquísima, mucha erudición de la gramática arábiga, que la notaría, si fuese necesario, y que en gramática no habría ningún morisco, ahora ni en tiempos pasados, que supiese notar ni ordenar los libros, la nota, dicciones ni frases, que es imposible; y que tienen muy buena ortografia y gran primor, y cualquiera docto arábigo lo entenderá con facilidad, porque no tienen corrompimiento en su nota ni en la gramática; y que el lenguaje y letra de estos libros es cosa antiquísima de mil o dos mil años, y que no puede haber embuste de nadie, y que los árabes modernos dirían que hacían barbarismos, y pone exemplos de algunas dicciones que son antiquísimas del tiempo de Mahoma, y la letra es diferentísima a la que ahora se $u s a^{40}$.

${ }^{38}$ Historia, p. 104.

${ }^{39}$ Texto publicado en El morisco granadino a base del citado ms. 6637 (fol. 173r y v) de la Biblioteca Nacional de Madrid.

${ }^{40}$ Los subrayados son nuestros; justamente por la circunstancia señalada en la última frase, los sucesivos traductores solían poner como condición para 
Creo que el pasaje transcrito no tiene desperdicio respecto a las especiales características de los libros según el proyecto de sus autores; más, si exceptuamos las diferencias gráficas, las restantes características, como la antigüedad, la erudición de la gramática arábiga, la elegancia y grandeza del estilo, etc., no están más que en la imaginación de sus protagonistas.

El segundo aspecto, a que antes aludí, es el ofrecimiento espontáneo que ambos moriscos hicieron para traducir el pergamino y los libros a raíz de su descubrimiento, persuadidos como estaban de que, ante la modificación gráfica de sus letras y la frecuente omisión de los puntos diacríticos, ningún traductor ajeno al proyecto sería capaz de descifrarlos. Así se inicia un largo y penoso camino - triunfalista sólo para unos cuantos ingenuos - y empieza la interminable búsqueda de traductores por parte de don Pedro de Castro, de los reyes y altos organismos del Estado español e incluso de la Santa Sede, cuando en 1643, y tras muchas vicisitudes y dilaciones sin cuento, llegan las ya famosas láminas a Roma - donde aún permanecen-, veinte años después de la muerte de Castro en 1623, siendo ya arzobispo de Sevilla.

Pues, bien, la razón fundamental esgrimida una y otra vez por el arzobispo y las autoridades españolas para justificar su demora en el envío de las láminas a Roma, tal como exigía la Santa Sede, era la búsqueda de nuevos traductores que realizaran una versión definitiva para enviar a la Curia Romana juntamente con los textos originales. Este fue el doloroso calvario de don Pedro de Castro, hombre de buena voluntad pero tan persuadido de la trascendencia de los libros, que vaciló siempre entre su obstinada creencia en la autenticidad de los mismos y el temor de ser engañado por los traductores a su servicio, con los que gastó cuantiosas sumas de dinero. Tal es la razón de que él mismo intentase aprender el árabe, aunque no nos consta llegase a conseguirlo: “. . .el V. Prelado... continuaba... con su propio estudio, aplicándose hombre de su edad, carácter y ocupaciones, a aprender la lengua arábiga, para hallarse instruido en todo lo necesario para el mayor acierto" ${ }^{41}$.

aceptar su trabajo, que se les facilitasen las versiones anteriores, sobre todo las de Miguel de Luna y Alonso del Castillo. Prosigue el testimonio de Miguel de Luna (ms. cit., ff. 173v-174r), que, en sustancia, coincide con el de Alonso del Castillo, sin aportar nada nuevo.

${ }^{41}$ Diego NiCOlÁs HeREdia BARRIONuevo, Mústico ramillete; histórico, chronológico, panegírico, biográfico de D. Pedro de Castro, Granada, 1741, p. 26; AlONSo, Los apócrifos del Sacromonte, p. 143 y nota 16. 
Confieso que desde hace bastantes años me ha interesado ese continuo desfile de traductores quemándose sus cejas sobre los arcanos textos granadinos; pero ahora no voy a utilizar aquí todas mis notas, sino recordar únicamente sus nombres, sin propósito exhaustivo, y remitiendo a quien se interese por algunos datos sobre cada uno de ellos, a los índices de mi monografía El morisco granadino Alonso del Castillo - para los primeros años - y del reciente libro del P. Alonso Los apócrifos del Sacromonte.

Incluiremos en esta nómina - prescindiendo ya de Miguel de Luna y Alonso del Castillo - a los siguientes traductores: el licenciado Luis Fajardo, antiguo catedrático de árabe de la Universidad de Salamanca; Francisco López Tamarid, racionero mayor de la catedral de Granada; Gregorio López Madera, alcalde de casa y corte, corregidor de Toledo y fiscal del rey en la Chancillería de Granada; Diego de Urrea, profesor durante algún tiempo en la Universidad de Alcalá y autor de un catálogo bilingüe -árabe y español - de los primeros fondos árabes de la Biblioteca Escurialense, compuesto tal vez en 159842; el conocido historiador de la sublevación morisca Luis del Mármol Carvajal; el P. Ignacio de las Casas, jesuita de origen morisco, que, tras una breve etapa inicial favorable a los libros, se convirtió en uno de los tres más decididos adversarios de los mismos, junto con Arias Montano y don Juan Bautista Pérez, obispo de Segorbe, aunque sin alcanzar, ni de lejos, la categoría intelectual de ambos; los dos médicos Gonzalo de Ayala y Jerónimo de Alcalá ${ }^{43}$; el sirio Marcos Dovelo, quien no hizo buenas migas con don Pedro de Castro por sus excesivas demandas; Francisco Gurmendi, encargado también de revisar los manuscritos árabes aprehendidos en un barco del sultán de Marruecos Muley Zaydán, antes de ingresarlos en la Biblioteca de El Escorial ${ }^{44}$; y fray Juan Bautista Hesronita, dominico y arzobispo maronita, que se intitulaba de Montelíbano.

En 1622 se intenta establecer la enseñanza del árabe en la propia abadía del Sacromonte, a fin de que allí mismo pudiesen trans-

${ }^{42}$ Publicado por el P. Nemesio Morata, "Un catálogo de los fondos árabes primitivos de El Escorial", AlAn, 2 (1934), 87-181; cf., también, Braulio Justel Calabozo, La Real Biblioteca de El Escorial y sus manuscritos árabes, Madrid, 1978, pp. 169, 221.

${ }^{43}$ Arias Montano tiene por más enterado al primero en la lengua antigua y por más hábil ai segundo en la "africana moderna", auñque "ambos son faltos de vocabulario aun para entender los libros de su profesión [médica], y ambos ignoran la gramática arábiga totalmente"; ALONSO, Los apócrifos del Sacromonte p. 134.

${ }^{44}$ Cf. JUSTEL, La Real Biblioteca de El Escorial, pp. 178-183. 
cribirse y traducirse los libros con más rapidez y mayor garantía; sin embargo, el proyecto fracasa por la incapacidad del pretendido profesor Sergio Maronita para enseñar la lengua y también para traducir las muestras de las láminas que se le ofrecen.

En esta serie nos queda todavía por mencionar al gran portaestandarte de los plúmbeos granadinos, Adán Centurión, marqués de Estepa, que, bajo la dirección del morisco Juan Bautista Centurión - al que dio su apellido - y del licenciado Sergio Maronita ya aludido, aprende el árabe y con la colaboración de ambos escribe su amplia y lujosa Información para la historia del Sacromonte... ${ }^{45}$, gastando también grandes sumas de dinero en la defensa de esta causa perdida.

Pero, aparte los hasta aquí citados, que por más o menos tiempo y con varia fortuna trabajaron de manera real en la traducción de los libros, momentos hubo en que se buscaron traductores en las Universidades de Alcalá, Valladolid y Salamanca, en Roma, Ferrara y Venecia, e incluso se llegó a pedir al embajador de España en Persia que allá buscase un intérprete adecuado. Aunque las gestiones no llegaron a buen fin, otros varios traductores estuvieron a punto de ser contratados para venir a España con igual finalidad, como, por ejemplo, el turco Cosme Dragut, mi hermano de hábito Francisco Martelloti, autor de las conocidas Instituciones lingua arabicae (publicadas en Roma, 1620), y los maronitas Gabriel Sionita y Victorio Scialag. Por último, incluso se llegó a pensar en el famoso orientalista holandés Thomas van Erpen, catedrático de la Universidad de Leiden e intérprete oficial de los Estados Generales, que moría en 1624, un año después de don Pedro de Castro, sin haber llegado a un acuerdo ${ }^{46}$.

Una vez que las láminas llegaron a Roma, y aparte la comisión cardenalicia que habría de juzgar su doctrina, fue designado un grupo de intérpretes encargados de la definitiva transcripción y traducción de las mismas, entre los que se encuentran nombres bien conocidos para los estudiosos del arabismo en Europa. For-

${ }^{45}$ Primera parte, Granada, 1632; obra reeditada por M. J. HAGERTY en la Editora Nacional, Biblioteca de visionarios, heterodoxos y marginados, Madrid, 1980, bajo el título general de Los libros plúmbeos del Sacromonte. En la misma editora y formando parte de la misma Biblioteca, había publicado IGNACIO GÓMEZ DE LIAÑo en 1975 Los juegos del Sacromonte, libro que yo calificaría de "historia-ficción".

${ }^{46}$ Sobre tales gestiones y seis cartas de contestación del holandés, junto con la traducción latina de cinco láminas de los libros plúmbeos, véase JUAN MAR. TÍNEZ RuiZ, "Cartas de Thomas van Erpen (Thomas Erpenius) en un archivo de Granada (1623-1624)", BRAE, 55 (1975), 265-306 
maban dicho grupo los jesuitas Atanasio Kircher y Juan Bautista Giattini; los franciscanos Bartolomé de Pettorano - gran propagandista y defensor de los libros - y Antonio de L'Aquila; el P. Ludovico Marraci (de la Congregación de Lucca de los Clérigos de la Madre de Dios) y el P. Felipe Guadagnolo (de los Clérigos Regulares Menores).

Condenados como apócrifos por el papa Inocencio XI en 1682 los libros plúmbeos, singular invención de un grupo de moriscos granadinos en un momento histórico difícil para su pervivencia, hoy apenas interesan sus doctrinas, sino tan sólo su lengua. En este aspecto se halla ahora trabajando mi discípulo Miguel José Hagerty, que intenta realizar una edición crítica del texto árabe con nueva traducción y comentario lingüístico. En su Memoria de Licenciatura - por mí dirigida y aún inédita - abordó el Kitã $b$ qa$w \bar{a} i d$ al-din, ya anteriormente aludido, y el Kitāb sifat al-qurbān, "Libro de la descripción de la misa". En su tesis doctoral, en curso de elaboración, estudiará otros dos de los libros: Ta'rīj haqĩqat $a l$-Anŷill, "Historia de la certidumbre del Evangelio" y Kitāb Maryam, "El Libro de María". La empresa no es fácil, mas confío en que su juventud, su seriedad científica y su capacidad de trabajo la llevarán a buen término, convirtiéndose, tal vez, en el último traductor de la serie, al menos por ahora.

DARIO CABANELAS

Universidad de Granada. 